\title{
REDES ORGANIZACIONAIS, UNIVERSIDADE E O ECOSSISTEMA DE EMPREENDEDORISMO: UM ESTUDO UTILIZANDO ANÁLISE DE REDES SOCIAIS
}

Matheus Roberto Marques Gasparoto ${ }^{1}$

Bruno Brandão Fischer ${ }^{2}$

${ }^{1}$ Departamento de Política Científica e Tecnológica / IG - Instituto de Geociências / Universidade Estadual de Campinas

${ }^{2}$ Universidade Estadual de Campinas 


\title{
REDES ORGANIZACIONAIS, UNIVERSIDADE E O ECOSSISTEMA DE EMPREENDEDORISMO: UM ESTUDO UTILIZANDO ANÁLISE DE REDES SOCIAIS
}

\begin{abstract}
Resumo
Ecossistemas de Empreendedorismo vêm recebendo crescente atenção dos pesquisadores devido à sua abordagem sistêmica e multidisciplinar. $\mathrm{O}$ objetivo desse trabalho é desenvolver uma metodologia, empregando Análise de Redes Sociais para identificar quem são e quais as mais relevantes organizações que compõem um Ecossistema Empreendedor. A pesquisa foi conduzida na Região Metropolitana de Campinas, reconhecido polo científico e tecnológico do Brasil, onde a Unicamp é responsável pela articulação de uma rede formada por cerca de 600 spin offs universitárias. A pesquisa consistiu em três etapas: i) identificar quais os tipos e quantas são as organizações que constituem o Ecossistema de Empreendedorismo; ii) identificar as relações formadas entre essas organizações; iii) construir os diagramas e indicadores das redes. Os resultados sugerem que a Universidade atua como um elo central do ecossistema analisado, atuando como eixo estruturante na dinâmica dessas relações.
\end{abstract}

Palavras-chave: Ecossistemas de empreendedorismo. Empreendedorismo acadêmico. Análise de redes sociais. Redes organizacionais.

\section{INTRODUÇÃO}

Partindo da premissa de que a proximidade geográfica é um vetor central na troca de conhecimento entre agentes, o olhar acerca da atividade empreendedora se orienta na dinâmica de relacionamentos no nível do Ecossistema de Empreendedorismo e da sua capacidade de fornecer recursos e relacionamentos para indivíduos e firmas (Alvedalen \& Boschma, 2017; Audretsch \& Belitski, 2017; Isenberg, 2010). Neste contexto, um agente de interesse central é a universidade, tendo em conta seu papel de desenvolvimento científico e tecnológico, capacidade de oferta de capital humano e mecanismos de transferência de conhecimento (Asheim et al., 2011; Bercovitz \& Feldman, 2006; Etzkowitz \& Leydesdorff, 2000). Em décadas recentes, crescente atenção vem sendo dedicada à capacidade destas instituições de gerar novos empreendimentos de cunho acadêmico. Por sua vez, estas empresas possuem reconhecido potencial de converter o conhecimento científico em negócios com capacidade de acelerar processos de desenvolvimento socioeconômico (Guerrero \& Urbano, 2012; Beckman et al., 2012).

Consequentemente, as universidades são frequentemente percebidas como eixos estruturantes destes Ecossistemas de Empreendedorismo, em que áreas próximas a estas instituições estão associadas a maiores níveis de atividade empreendedora (Rothaermel \& Ku, 2008; Schaeffer et al., 2018). Não obstante, apesar da ampla aderência destas perspectivas em estudos relacionados à dinâmica geográfica do empreendedorismo, o foco analítico reside no estabelecimento de lógicas causais entre os elementos, deixando lacunas quanto a questões envolvendo a dinâmica de relacionamentos entre os agentes que compõem tais ecossistemas (Alvedalen \& Boschma, 2017). Esta situação é insatisfatória desde um ponto de vista analítico, uma vez que a própria lógica de Ecossistemas de Empreendedorismo se constrói sobre as trocas e conexões existentes entre suas dimensões constituintes (Mason \& Brown, 2014).

Assim, o Ecossistema Empreendedor é o objeto de estudo sobre o qual essa pesquisa se desenvolve. Tais estruturas produtivas não são constituídas apenas por uma universidade e pelas empresas que se relacionam com ela, mas também por demais instituições de suporte ao

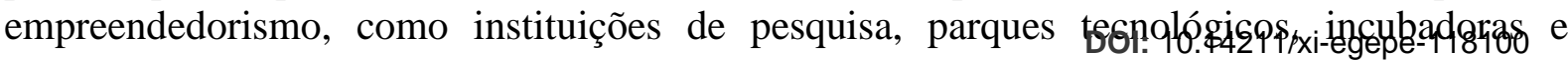


As unidades de análise utilizadas neste estudo, portanto, são organizações: as instituições de apoio ao empreendedorismo; e as empresas, majoritariamente spin offs da Unicamp.

O diferencial dessa proposta de pesquisa é aplicar a metodologia denominada Social Network Analysis (Análise de Redes Sociais) para subsidiar análises que complementam estudos anteriores sobre Ecossistemas de Empreendedorismo realizados com outros métodos. Essa metodologia vem experimentando, a partir dos anos 2000, um novo impulso em sua utilização, evolução atribuída em parte pelos avanços das tecnologias da informação e comunicação, capazes de criar dados completos sobre redes e equipamentos poderosos para processamento. Curiosamente, o advento das plataformas de redes sociais, como o Facebook, também tem grande responsabilidade na popularidade da metodologia homônima (Burt et al., 2013).

O potencial do emprego dessa metodologia é evidenciado por Alvedalen e Boschma (2017) em diversos aspectos. Primeiro, por permitir uma análise verdadeiramente sistêmica dos Ecossistemas, visto que sua complexidade reside no fato que o objeto de estudo é composto por atores heterogêneos e pelas relações estabelecidas entre eles. Segundo, a metodologia possibilita operacionalizar estudos multiescalares, visto que a delimitação da escala geográfica dos Ecossistemas ainda é uma questão em aberto. Trabalhos anteriores focaram clusters de empresas, cidades, regiões e países (e.g. Ács et al, 2014; Audretsch \& Belitski, 2017), ou ainda que o Ecossistema é a própria universidade e o seu entorno (Hayter et al., 2018).

Com o exposto acima, propõe-se responder à seguinte pergunta de pesquisa: Como identificar as organizações que constituem um Ecossistema Empreendedor a partir de Universidades Empreendedoras atuantes nessa estrutura? Desta forma, este estudo se propõe a desenvolver uma proposta metodológica para identificar quem são e quais as mais relevantes organizações que compõem um Ecossistema Empreendedor.

Como resultado principal dessa pesquisa tem-se a construção e análise da rede formada pelos atores do Ecossistema Empreendedor da Região Metropolitana de Campinas (RMC) a partir da Unicamp e de suas spin offs. Esta abordagem possibilitou uma melhor compreensão sobre os ecossistemas em regiões metropolitanas de países em desenvolvimento, sobre quais são as instituições que os compõem, quais as suas características, quais as instituições mais relevantes e como se dá a dinâmica de interações no âmbito do ecossistema. Outro resultado importante foi contribuir com a escassa literatura sobre relações externas aos Ecossistemas Empreendedores. Por fim, o estudo destaca a importância que algumas instituições de apoio ao empreendedorismo, incluindo grandes universidades de pesquisa, possuem em estruturar a governança das redes sobre as quais se fundamental os Ecossistemas de Empreendedorismo.

Após esta seção introdutória o restante do artigo é organizado da seguinte forma: A seção 2 compreende o referencial teórico utilizado como base para o desenvolvimento conceitual e analítico da pesquisa, delineando o papel da universidade empreendedora, o contexto dos Ecossistemas de Empreendedorismo e aplicações da metodologia de Análise de Redes Sociais para estudos da atividade empreendedora. A seção 3 apresenta os aspectos metodológicos envolvidos com a etapa empírica da pesquisa. Os resultados são elencados na seção 4 e a seção 5 conclui com uma discussão dos principais achados, limitações e sugestões para pesquisas futuras.

\section{REFERENCIAL TEÓRICO}

O marco teórico dessa pesquisa é baseado em três abordagens principais, sobre as quais foram atribuídas as subseções a seguir: Empreendedorismo e Universidades; Ecossistemas Empreendedores, Redes organizacionais e aglomerações produtivas; e, por fim, a metodologia Análise de Redes Sociais aplicada ao empreendedorismo. 
Atualmente, o empreendedorismo é o principal objeto de estudo de uma área equiparável a uma disciplina científica, comumente nomeada por estudos em empreendedorismo, definido por Shane e Venkataraman (2000, p. 218) como "o estudo das fontes de oportunidades; os processos de descoberta, avaliação e exploração de oportunidades; e o conjunto de indivíduos que os descobrem, avaliam e exploram " (tradução dos autores). Para Van de Ven (1993), a atividade empreendedora consiste em um desenvolvimento orgânico associado a acontecimentos envolvendo instituições, recursos e indivíduos, compreendendo, assim, uma série de atores que transcendem as fronteiras das organizações.

O empreendedorismo é, então, um fenômeno complexo no qual é possível encontrar diversas dimensões de análise. A atividade empreendedora com origem na academia foi reconhecida como uma importante fonte de inovação, de criação de empregos e de crescimento econômico. A partir do ciclo de inovações dos anos 1990, em que as universidades tiveram papel relevante na criação de empresas de sucesso, os governos passam a interpretar cada vez mais o empreendedorismo e a inovação como meios para solucionar suas demandas econômicas e sociais (Carree \& Thurik, 2003). Neste sentido, o empreendedorismo acadêmico representa um vetor central nos processos de comercialização de tecnologias geradas pelas instituições de ensino superior (Siegel \& Wright, 2015).

Nesse contexto Etzkowitz (1998; 2004) elabora o conceito de universidade empreendedora, visando integrar o desenvolvimento econômico e social às responsabilidades universitárias clássicas, a saber, atividades de ensino, pesquisa e extensão. Essa concepção engloba atividades como a pesquisa colaborativa entre universidades e empresas, contratos de pesquisa, patenteamento e licenciamento de tecnologias, bem como o empreendedorismo, materializado através da criação de spin offs (Bercovitz \& Feldman, 2006; Grimaldi et al., 2011).

O termo spin off foi criado originalmente para designar o processo de transferência de tecnologia dos grandes programas tecnológicos públicos militares ou civis para o setor produtivo (Furtado, 2005). Conotações mais atuais, entretanto, ampliam o conceito para spin off universitária (university spin off ou USO) referindo-se à transferência de tecnologia criados no contexto acadêmico. As spin offs acadêmicas ou universitárias foram bem documentadas em trabalhos que explicam, por exemplo: as origens do Vale do Silício (Saxenian, 1990); os setores de Tecnologia de Informação e de Biotecnologia (Chiesa \& Piccaluga, 2000); o papel desempenhado por universidades como Stanford, Harvard e o MIT, nos EUA, e Cambridge no Reino Unido (Wessner, 2013).

Alvedalen e Boschma (2017) apontam que novos empreendimentos se encontram incorporados nas relações sociais, sendo que a sua criação ocorre também em ecossistemas nos quais as universidades estão presentes e nos quais diferentes relações são estabelecidas entre os atores. As universidades, portanto, são elementos cruciais para o estabelecimento e desenvolvimento de novas firmas. Desta forma, universidades de pesquisa, que possuem uma estrutura de suporte em termos de escritórios de transferência tecnológica, parques científicos e incubadoras, são propensas a contribuir com a geração de novos empreendimentos (GalanMuros \& Davey, 2017).

\subsection{Ecossistemas Empreendedores, redes organizacionais e aglomerações produtivas}

O conceito de Ecossistema de Empreendedorismo (EE) tem atraído grande atenção em um período relativamente curto de tempo (Alvedalen \& Boschma, 2017). Esse novo conceito coloca em evidência o caráter sistêmico de um grupo heterogêneo de atores que atuam para estimular o empreendedorismo. O conceito foi pela primeira vezompregado e definido por 
geográfica local comprometida com o desenvolvimento sustentável através do apoio e facilitação de novos empreendimentos sustentáveis" (tradução dos autores). Já Stam e Spigel (2017, p. 1) definem Ecossistema Empreendedor como "um conjunto de atores e fatores interdependentes, coordenados de tal forma que possibilitem o empreendedorismo produtivo dentro de um determinado território" (tradução dos autores). A definição mais detalhada para o termo, e que será adotada para a condução dessa pesquisa, foi a encontrada em Mason e Brown (2014), que definiram estes ecossistemas como:

um conjunto de atores interconectados e relacionados ao empreendedorismo (tanto potenciais quanto existentes), organizações empreendedoras (por exemplo, firmas, capitalistas de risco, investidores-anjo, bancos), instituições (universidades, agências do setor público, órgãos financeiros) e processos empresariais (ex. taxa de natalidade de firmas, número de empresas de alto crescimento, nível de "empreendedorismo de alto impacto", número de empreendedores em série, grau de orientação para sellout dentro das empresas e níveis de ambição empreendedora) que formal e informalmente se fundem para conectar, mediar e governar o desempenho dentro do ambiente empreendedor local. (Mason \& Brown, 2014, p. 5). Tradução dos autores.

A justificativa para tal escolha, deve-se primeiramente pela grande atenção dada aos diferentes atores que compõe o Ecossistema Empreendedor, visto que a unidade de análise utilizada na proposta dessa pesquisa são organizações: empresas e instituições de apoio ao empreendedorismo. A motivação para esse artigo surge de uma necessidade em se compreender melhor quais são as organizações que compõem um EE. Sobre esse questionamento, tem-se observado a criação de ambientes empreendedores ou também chamados habitats de inovação (HIs), às vezes denominados como ambientes de inovação. Exemplos desses ambientes empreendedores são incubadoras de empresas, parques tecnológicos e aceleradoras de empresas, programas de aceleração e espaços de coworking. Tais ambientes oferecem aos proponentes de ideias inovadoras e empresas startups um espaço propício para o desenvolvimento de suas atividades, amparado por um suporte em gestão, além da possibilidade de maior interação entre empresas e universidades, por meio dos seus pesquisadores e laboratórios. Dado este contexto, universidades têm estimulado cada vez mais a criação desses ambientes empreendedores dentro ou nos arredores de seus campi (Bagnato, 2017).

Adicionalmente, ecossistemas podem ser interpretados como áreas geograficamente delimitadas e permeadas por componentes mutuamente dependentes (Auerswald, 2015; Napier \& Hansen, 2011). Dito de outra forma, aglomerações produtivas podem ser interpretadas como redes interorganizacionais territorializadas (Silva \& Neves, 2013), sendo os Ecossistemas Empreendedores uma forma específica e mais atual de tais aglomerações. Para a formação de redes, o condicionante geográfico é de especial relevância, pois os laços formados estimulados pela proximidade geográfica apresentam características que vão além das tradicionais relações comerciais, proporcionando a formação de redes informais de colaboração, embebidas por hábitos, convenções e normas específicos para a rede em questão (Conti, 2005). Esse sistema próprio de coordenação (local) que estabelece como serão as relações entre as empresas e demais instituições (Cassiolato \& Lastres, 2002).

As formas de aglomerações produtivas propostas até então não consideram as particularidades dos novos empreendimentos (sejam eles spin offs ou startups), nem como esses alteram as configurações das redes organizacionais à qual pertencem (Aaboen et al., 2016). Não se propõe nessa pesquisa encerrar por definitivo a questão de como os novos empreendimentos se inserem em redes organizacionais, pois ainda é um tema em desenvolvimento. O que é possível inferir é que os papéis desempenhados por esse tipo de empreendimento vão além da superespecialização, subordinação e integração vertical ou horizontal preconizados pelas teorias mais difundidas sobre aglomerações produtivas e redespimitero.19anizizacigepais.1 foono 
empreendimentos, e não das empresas-líderes, alterando substancialmente a rede qual estão inseridos.

\subsection{Análise de Redes Sociais (ARS) aplicada ao Empreendedorismo}

A relevância do estudo das redes para o Empreendedorismo reside também em interpretar os relacionamentos estabelecidos entre os agentes como um canal por onde fluem recursos diversos. Esse mecanismo não fica restrito somente aos estágios iniciais do novo empreendimento (start-up), visto que empreendedores continuam a cultivar e a depender das redes formadas entre eles e as demais instituições para obter informações de negócios, aconselhamento, resolução de problemas, capital humano, recursos financeiros e muitos outros recursos (Hoang \& Antoncic, 2003). Aproveitar os benefícios de estar inserido numa rede, entretanto, vai depender em grande medida do posicionamento que um determinado ator ocupa nessa rede, o qual pode ser observado num diagrama de rede. Uma vez formado esse diagrama, será possível verificar, através das estatísticas de rede, a magnitude do fluxo de recursos e em última instância, os resultados dos empreendimentos que formam a rede.

A questão da formação de redes no contexto do empreendedorismo vem recebendo a atenção dos pesquisadores desde a década de 1980. Uma parte dessa literatura debruça-se em investigar como variações nas características das redes implicam em variações em desempenho dos empreendimentos. Parece haver um amplo consenso de que as redes influenciam nos resultados dos empreendimentos, principalmente das novas firmas. O que não existe, entretanto, é uma teoria unificadora que explique quais as configurações das redes otimizam os benefícios para cada estágio do desenvolvimento da firma. Avançando nesse sentido, Stam et al. (2013) conduziram um trabalho que sistematizou a produção científica sobre como as redes pessoais dos empreendedores influenciam o desempenho dos novos empreendimentos. Neste trabalho descobriu-se que essa relação é contextual, ou seja, a correlação entre redes e performance depende também de condicionantes, como a idade da firma,; o mercado de atuação e o nível do desenvolvimento econômico do país onde a firma está instalada.

A vasta literatura sobre a importância das redes nos estudos sobre empreendedorismo, entretanto, não foi o suficiente em estabelecer uma abordagem holística, que considere os diversos aspectos inter-relacionados observados no fenômeno empreendedor. Estudos recentes sobre o tema convergem em afirmar que a natureza sistêmica do empreendedorismo ainda é pouco desenvolvida (Ács et al., 2014; Qian et al., 2013; Alvedalen \& Boschma, 2017). As principais fraquezas na literatura sobre Ecossistemas de Empreendedorismo, como apontam Alvedalen e Boschma (2017), e que servem como guia para pesquisas futuras no tema, são:

i. Falta explicitar com clareza o que é causa e o que é efeito, visto que o Ecossistema Empreendedor é constituído por diversos elementos;

ii. Apesar de ser um conceito sistêmico, a teoria de redes está sendo subutilizada, faltando clareza de que modo esses elementos estão conectados e quais interações são as mais relevantes;

iii. Falta de entendimento sobre quais instituições, e em qual escala, impactam a estrutura e performance do EE;

iv. Ausência de estudos comparativos entre EE e de estudos multiescalares;

v. Ausência de estudos dinâmicos, que considerem a evolução do EE durante o tempo.

A metodologia de Análise em Redes Sociais apresenta um grande potencial em avançar nos estudos em Ecossistemas Empreendedores, resolvendo parte das deficiências

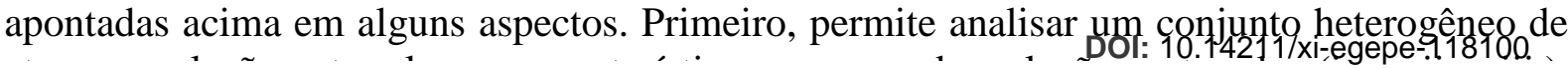


Segundo, ao constituir-se de um método científico formal, possui procedimentos estabelecidos para coleta e interpretação de dados, e possui também um conjunto de métricas específicas para redes, normatizando a prática e facilitando análises comparativas (item iv.). Terceiro, redes são constructos que não são limitados pelo tamanho da escala, ou ainda permite estabelecer relações entre redes de escalas distintas (itens iii. e iv.). Por último, existe a possibilidade de se realizar estudos dinâmicos em redes (item v.).

\section{METODOLOGIA}

A presente pesquisa busca descrever e analisar as redes formadas pelas organizações do Ecossistema Empreendedor da Região Metropolitana de Campinas. Os dados primários da etapa quantitativa da pesquisa foram coletados a partir de um questionário, os quais foram desenvolvidos com base na revisão da metodologia de Análise de Redes Sociais utilizando o manual de Wasserman e Faust (1994). Complementarmente, trabalhos empíricos utilizando este método foram consultados para a construção do instrumento de coleta de dados (Ruffoni, 2010; Pamplona, 2012; Diánez \& Camelo, 2017).

Como resultado desta primeira etapa foram elaborados dois questionários: Questionário 1, para as instituições de apoio ao empreendedorismo e Questionário 2, para empresas. Os questionários visaram coletar dados relacionais que as instituições respondentes têm com demais atores através da identificação de agentes com os quais os respondentes se envolvem em fluxos de informação. Sendo assim, duas conexões quaisquer foram consideradas como uniformes em suas características. Pré-testes dos questionários foram realizados em Outubro de 2018 junto a organizações estudantis da Universidade Estadual de Campinas, permitindo a realização de ajustes nos instrumentos. As versões finais foram disponibilizadas na plataforma online JotForm.

Para a coleta de dados foi empregada a técnica snowball (Wasserman \& Faust, 1994). Esta técnica consiste em formar a rede em etapas sucessivas, as quais aumentam a cada iteração. A rede começa a partir dos primeiros respondentes, que irão citar outros nomes nas respostas do questionário. A rede ampliada é formada na segunda iteração, onde envia-se o questionário para os nomes obtidos na primeira iteração. Esse processo é repetido até que se obtenha um número adequado de respostas. Para esta pesquisa foram realizadas duas iterações.

A Agência de Inovação da Unicamp (Inova) auxiliou no processo de aplicação dos instrumentos. Os envios ocorreram em duas etapas: dezembro de 2018 e janeiro de 2019. Além do uso dos dados de contato de spin offs da Inova, os pesquisadores obtiveram contatos através da participação em dois eventos para a promoção do empreendedorismo, a saber, o Inova Campinas e a Semana Global do Empreendedorismo. Ao final das etapas de coleta de dados, em fevereiro de 2019, foram compiladas 51 respostas válidas. A rede formada ao final da coleta de dados apresentava a composição de 540 nós (instituições) e 1.184 conexões.

As 51 instituições que responderam ao questionário foram 35 empresas e 16 instituições de apoio ao empreendedorismo. Das empresas, a maioria (31) eram spin offs da Unicamp e constituíram a categoria de respondentes de maior número, cumprindo com êxito o planejado para a coleta de dados, que mirava atingir prioritariamente essa parcela da população. As instituições de apoio ao empreendedorismo formaram um grupo mais diverso de instituições, sendo que responderam ao questionário Organizações da Sociedade Civil $(n=6)$, Institutos de Pesquisa (4), Órgãos da Administração Pública Municipal (2), Instituição de Ensino/Departamento de Instituição de Ensino (1), Entidade Estudantil (1), Conselho de Apoio à Pesquisa (1) e Aceleradora de Empresas (1).

A ferramenta empregada para criar, manipular, aperfeiçoar e visualizar as redes foi o software Gephi. Esta abordagem permitiu, além da criação dos respectivos grafos, o cálculo das principais estatísticas das redes analisadas. 


\section{RESULTADOS}

Nessa seção serão feitas as descrições das redes e sub-redes de acordo com as prescrições da metodologia Análise de Redes Sociais. Têm-se ao todo cinco redes, sendo que a principal distinção entre elas está na representação dos nós. Nas redes diagramadas na Figura 1 os nós representam as organizações de forma individualizada, ou seja, cada nó simboliza uma organização. Por outro lado, na rede da Figura 2 os nós são agrupados de acordo com as categorias das organizações.

Para as redes representadas na Figura 1, as estatísticas de centralidade de rede escolhidas foram: grau; grau ponderado; grau de entrada ponderado; centralidade de proximidade; centralidade de intermediação e centralidade de autovetor (conferir a subseção 4.3). Para as redes da Figura 2 foram utilizadas somente grau e grau de entrada ponderado. Para todas as redes, empregaram-se as mesmas estatísticas gerais, a saber: quantidade de nós, de vértices, de conexões e de componentes; diâmetro da rede; comprimento médio de caminho; densidade da rede; grau médio e grau ponderado médio.

\subsection{Redes formadas por nós desagrupados}

As redes formadas por nós desagrupados podem ser visualizadas na Figura 1 e suas estatísticas gerais de rede estão compiladas na Tabela 1. A Rede A é dita completa pois representa as instituições internas e externas à Região Metropolitana de Campinas. A Rede B é uma sub-rede da Rede A, e nela encontram-se somente as instituições sediadas na RMC. A Rede C e a Rede D são sub-redes da Rede B, sendo que a primeira é uma rede formada por instituições de apoio ao empreendedorismo da RMC e na segunda constam somente empresas da RMC. O número de conexões é maior que o número de vértices, pois alguns vértices representam mais do que uma conexão, ou seja, são vértices ponderados. A espessura dos vértices varia proporcionalmente com o número de conexões. Já o tamanho dos nós representa a estatística denominada grau de entrada ponderado. A visualização da rede tende a colocar os nós com maiores graus de entrada ponderado no centro da rede, e aqueles com poucas conexões, ou seja, menores graus, na periferia.

Da esquerda para a direita da Tabela 1 as redes vão ficando cada vez menores em termos de quantidades de nós, vértices e conexões, bem como em termos de diâmetro e comprimento médio de caminho. As redes menores também se apresentam mais fragmentadas do que as redes maiores em termos de componentes e de nós desconectados. A Rede $\mathrm{C}$ e a Rede D são aquelas quais os nós apresentam menor conectividade, visto que as estatísticas de grau médio e grau ponderado médio apresentam valores mais baixos.

É possível derivar algumas conclusões importantes a partir da análise comparativa entre estas redes. Comparando-se a Rede A com a Rede B, percebe-se que o Ecossistema Empreendedor estudado é constituído por elementos internos (instituições sediadas na RMC) e externos (instituições sediadas fora da RMC). A conectividade da rede formada somente por elementos internos ao Ecossistema Empreendedor (Rede B), entretanto, é maior, por apresentar maior densidade e maiores valores para grau médio e grau ponderado médio. A presença de nós desconectados na Rede B evidencia que muitas instituições externas ao ecossistema têm a função de conectar elementos internos de forma indireta. Uma consideração importante a ser feita é que muitas instituições relevantes para a Rede A (rede completa), mas que não estão na Rede B, continuam sendo relevantes para o Ecossistema. O recorte feito para que na Rede B constassem somente instituições sediadas na Região Metropolitana de Campinas atende uma necessidade da definição de Ecossistema Empreendedor em se delimitar uma região para o objeto de estudo (Bruns et al., 2017). 


\section{Figura 1. redes formadas por nós desagrupados}

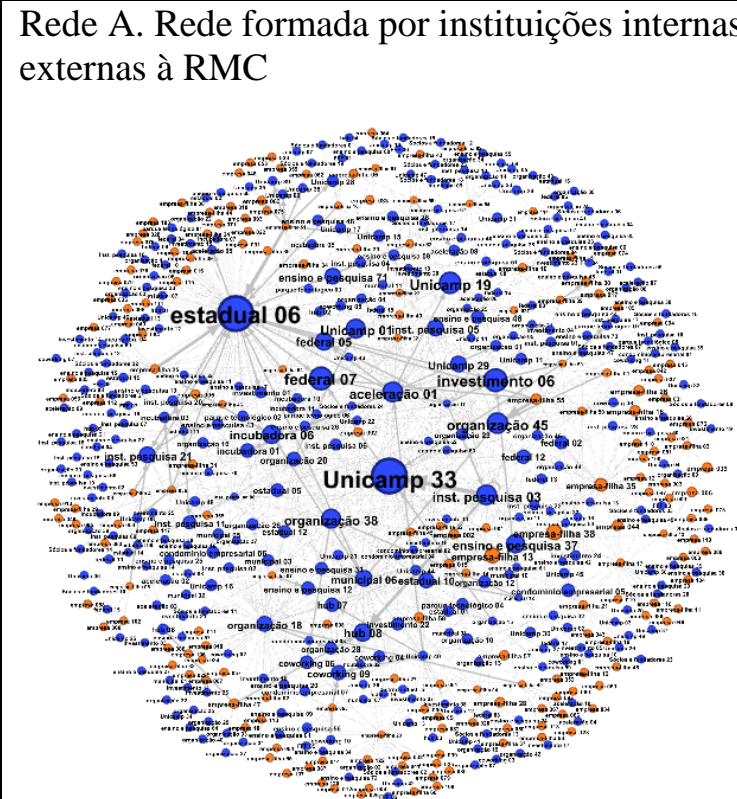

Nós azuis: instituições de apoio ao empreendedorismo

Nós laranjas: empresas

Rede C. Rede formada por instituições de apoio ao empreendedorismo sediadas na RMC

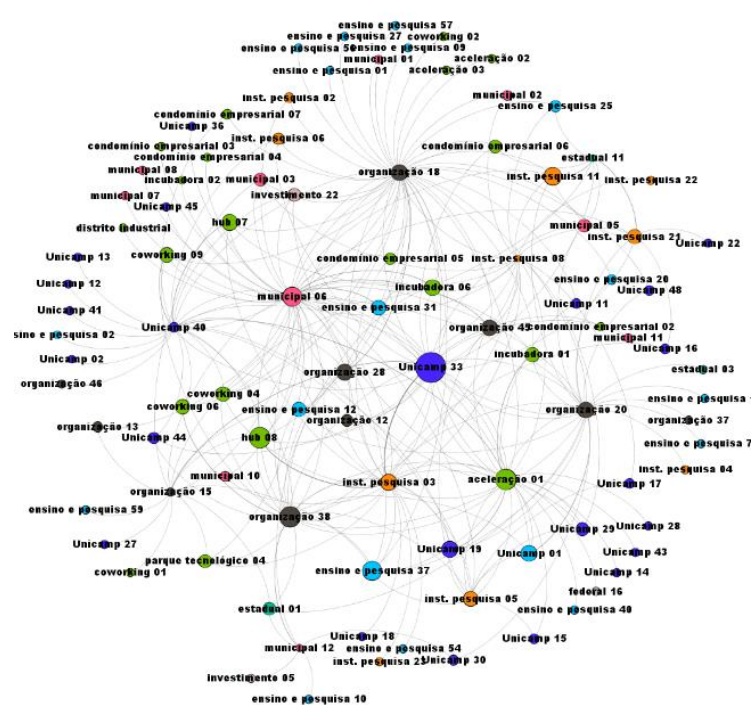

Fonte: elaboração própria, utilizando o software Gephi.

Notas: em todas as redes o tamanho do nó representa o grau de entrada ponderado e a espessura do vértice o peso da ligação. Apesar da visualização desconsiderar os nós desconectados, as estatísticas foram calculadas considerando-se todos os nós para não gerar viés nas interpretações.
Rede B. Rede formada por instituições internas à $\mathrm{RMC}$

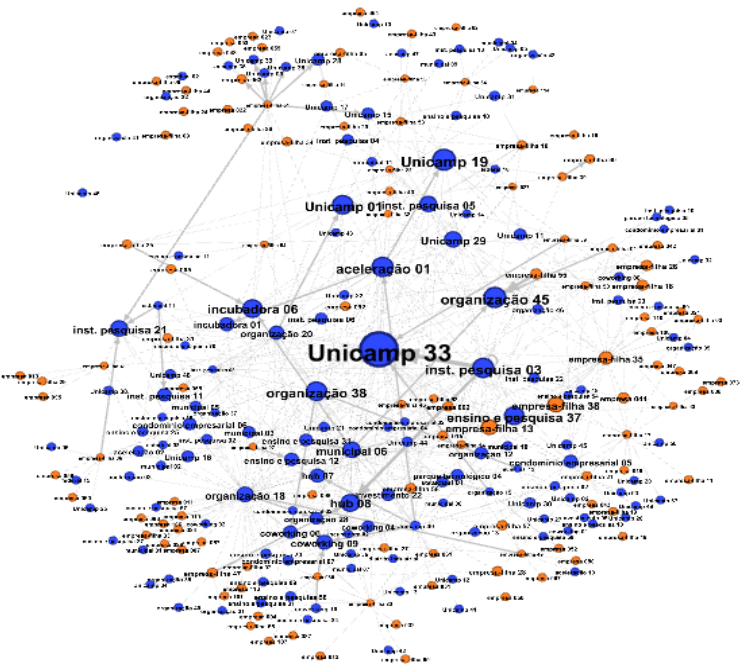

Nós azuis: instituições de apoio ao empreendedorismo

Nós laranjas: empresas

Rede D. Rede formada por empresas sediadas na RMC

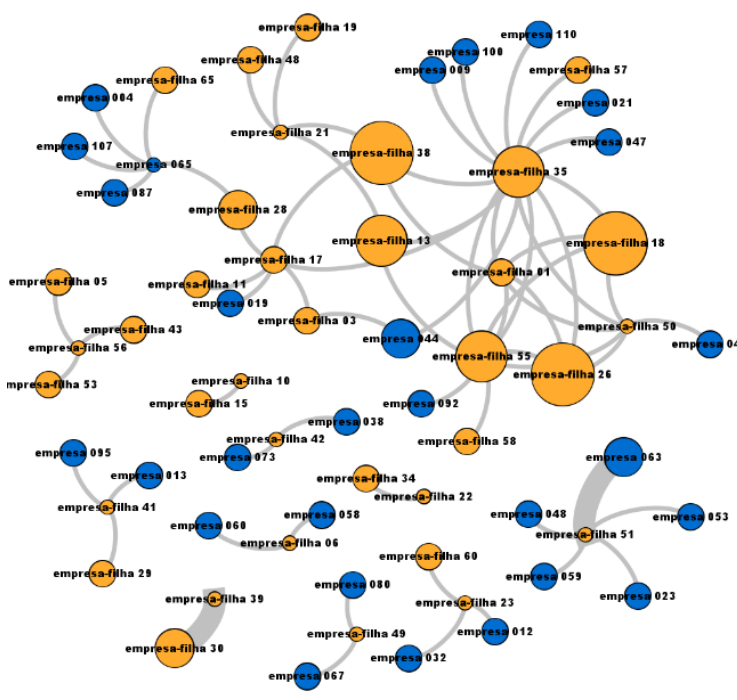

Nós laranjas: spin offs da Unicamp

Nós azuis: empresas não-spin offs da Unicamp 
Tabela 1. estatísticas gerais para as redes de nós desagrupados

\begin{tabular}{|c|c|c|c|c|}
\hline $\begin{array}{l}\text { Estatísticas } \\
\text { gerais de rede* }\end{array}$ & Rede A & Rede B & Rede C & Rede D \\
\hline nós & 540 & $\begin{array}{c}254(47,04 \% \text { da } \\
\text { Rede A) }\end{array}$ & $\begin{array}{l}98 \text { visíveis, } 143 \text { no total } \\
(56,30 \% \text { da Rede } B)\end{array}$ & $\begin{array}{l}64 \text { visíveis, } 111 \text { no total } \\
\text { (43,70\% da Rede B) }\end{array}$ \\
\hline vértices & 1.107 & $\begin{array}{c}562(50,77 \% \text { da } \\
\text { Rede A) }\end{array}$ & 254 (45,19\% da Rede B) & $68(12,10 \%$ da Rede B $)$ \\
\hline conexões & 1.184 & $\begin{array}{c}601(50,76 \% \text { da } \\
\text { Rede A) }\end{array}$ & $274(45,59 \%$ da Rede B) & $70(11,65 \%$ da Rede B) \\
\hline componentes & 2 & $\begin{array}{l}16 \text { ( } 1 \text { componente } \\
\text { principal e } 15 \text { nós } \\
\text { desconectados) }\end{array}$ & $\begin{array}{l}46 \text { ( } 1 \text { componente } \\
\text { principal e } 45 \text { nós } \\
\text { desconectados) }\end{array}$ & $\begin{array}{c}58 \text { (1 componente } \\
\text { principal, } 11 \\
\text { componentes menores e } \\
47 \text { nós desconectados) }\end{array}$ \\
\hline diâmetro & 6 & 5 & 5 & 3 \\
\hline $\begin{array}{l}\text { comprimento médio } \\
\text { de caminho }\end{array}$ & 2,708 & 2,638 & 2,205 & 1,529 \\
\hline densidade & 0,004 & 0,009 & 0,013 & 0,006 \\
\hline grau médio & 2,05 & 2,213 & 1,176 & 0,613 \\
\hline $\begin{array}{l}\text { grau ponderado } \\
\text { médio }\end{array}$ & 2,193 & 2,366 & 1,916 & 0,631 \\
\hline
\end{tabular}

Fonte: elaboração própria, utilizando o software Gephi. *as estatísticas foram calculadas considerando-se todos os nós para não inferir em interpretações errôneas.

Comparando-se a Rede C (instituições de apoio ao empreendedorismo da RMC) com a Rede D (empresas da RMC), percebe-se que, apesar de apresentarem uma quantidade de nós com pouca diferença, o tamanho e conectividade da Rede $\mathrm{C}$ é significativamente maior. Ainda mais, a Rede D é mais fragmentada e menos densa, apresentado menores níveis de conectividade. Este resultado sugere que as instituições de apoio ao empreendedorismo são mais importantes para o ecossistema estudado em termos de interatividade e cumprem o papel de integrar empresas. As empresas são o output esperado em um Ecossistema de Empreendedorismo, entretanto não são percebidas como as organizações mais relevantes na dinâmica de relacionamentos observada neste estudo. Como exceção, desponta na Rede D um conjunto de empresas conectadas representado pelo componente maior, na metade superior do diagrama, formado majoritariamente por spin offs da Unicamp consideradas relevantes através das estatísticas de rede (principalmente a estatística grau de entrada ponderado).

\subsection{Classificando as organizações do EE}

Nesta etapa, as organizações foram classificadas em 11 categorias distintas. A rede representada na Figura 2 foi criada para se analisar o fluxo de informação entre as categorias. As duas principais diferenças da Rede E em relação às outras são: 1) os nós foram agrupados de acordo com a categoria das organizações, ou seja, cada nó da Rede E representa todo o conjunto de instituições com a mesma classificação; 2) na Rede E o peso do vértice, visualizado de acordo com a sua espessura, passa a ser um elemento mais importante para a interpretação da rede, pois representa todo fluxo de informação entre duas categorias. O tamanho dos nós representa o grau de entrada ponderado, a principal estatística empregada na pesquisa pois está diretamente associada com o prestígio ou importância que cada nó possui na rede. Nesse quesito, a categoria "espaços/ambientes de empreendedorismo" apresentaram maior grau de

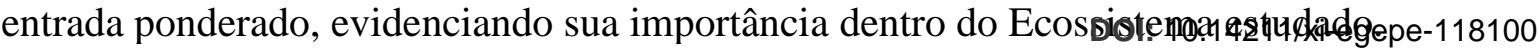


Figura 2. Rede formada por nós agrupados de acordo com as categorias das organizações (Rede E)

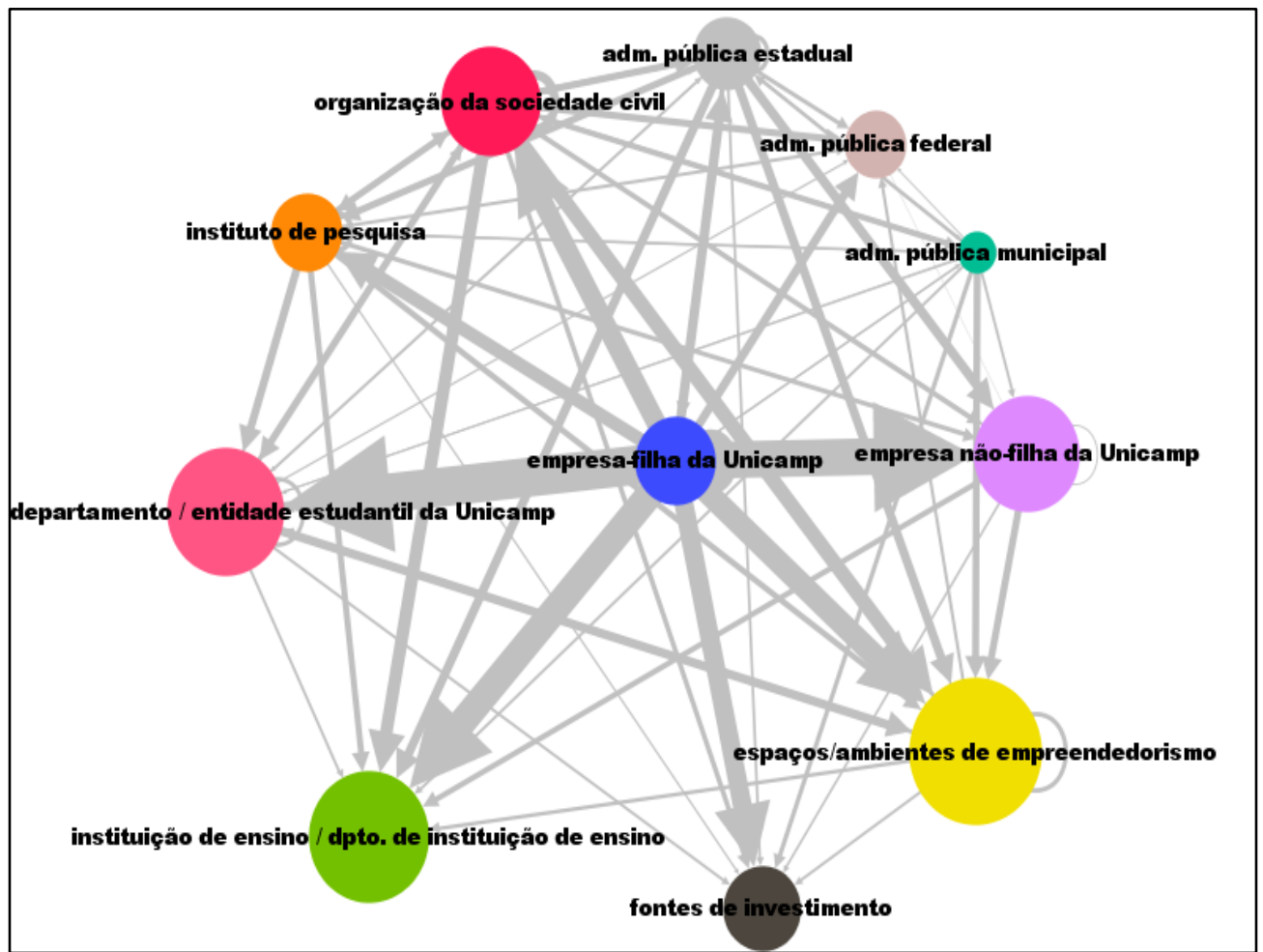

Fonte: elaboração própria, utilizando o software Gephi.

Nota: A nomenclatura "empresa-filha da Unicamp" corresponde ao conceito de spin off universitária.

Assim, a Rede E permite evidenciar as conexões estabelecidas entre diferentes dimensões do Ecossistema de Empreendedorismo, incluindo o papel das universidades e institutos de pesquisa, infraestruturas apoio ao empreendedorismo, agentes financiadores, e o governo, permitindo observar um alto grau de alinhamento com as estruturas ecossistêmicas propostas pela literatura (e.g. Mason \& Brown, 2014).

\subsection{Identificando as organizações mais importantes do EE}

Foi possível identificar de modo individualizado quais são as organizações mais importantes para o EE estudado. Para chegar nesse resultado, aplicou-se 6 medidas de centralidade distintas para todas as 540 organizações da rede completa (Rede A), organizadas de forma decrescente em seus valores, como mostra a Tabela 2. Posteriormente sintetizou-se, na Tabela 3, as organizações que mais apareceram nos rankings de centralidade da Tabela 2. A frequência máxima que cada organização pode constar nos rankings, portanto, é seis, ou seja, uma vez para cada estatística. Na Tabela 3, porém, são apresentadas somente as organizações com frequência igual ou maior a 3.

As organizações consideradas mais importantes de todas são aquelas que apresentam a frequência máxima nos rankings de centralidade, a saber: um espaço/ambiente de empreendedorismo (aceleração 01), um órgão da administração pública estadual (estadual 06), um instituto de pesquisa (inst. pesquisa 03), um órgão da administração pública municipal (municipal 06), uma organização da sociedade civil (organização 38) e um departamento da Unicamp (Unicamp 33). Faz-se necessário destacar a diversidade do conjunto de organizações mais importantes para o EE, visto que são de categorias distintas.

A Unicamp demonstra sua importância para o EE de duas formas, tanto através de seus

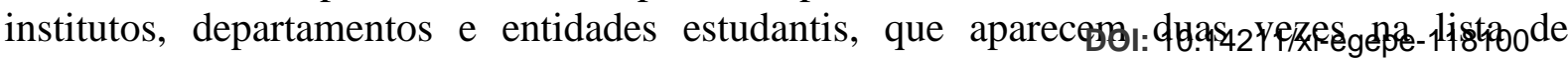


ISSN: 2525-7838 | BELO HORIZONTE/MG

EMPREENDEDORISMO E PEQUENOS NEGÓCIOS - DESAFIOS, OPORTUNIDADES E CONTRIBUIC̣ÕES PARA O DESENVOLVIMENTO TERRITORIAL SUSTENTÁVEL

\begin{tabular}{|c|c|c|c|c|c|c|c|c|c|c|c|c|}
\hline \multirow{2}{*}{ Rank } & \multicolumn{2}{|l|}{ Grau } & \multicolumn{2}{|c|}{ Grau ponderado } & \multicolumn{2}{|l|}{ entrada } & \multicolumn{2}{|c|}{ proximidade } & \multicolumn{2}{|c|}{ intermediação } & \multicolumn{2}{|c|}{ Centralidade de autovetor } \\
\hline & Codinome & Valor & Codinome & Valor & Codinome & Valor & Codinome & Valor & Codinome & Valor & Codinome & Valor \\
\hline 1 & estadual 06 & 124 & estadual 06 & 141 & estadual 06 & 36 & organização 18 & 0.49235 & estadual 06 & 5.697 .253 .265 & estadual 06 & 1 \\
\hline 2 & organização 18 & 81 & organização 18 & 83 & Unicamp 33 & 36 & municipal 06 & 0.480326 & inst. pesquisa 03 & 1.925 .971 .465 & Unicamp 33 & 0,973059 \\
\hline 3 & Unicamp 33 & 75 & Unicamp 33 & 81 & federal 07 & 20 & estadual 06 & 0.475806 & organização 18 & 1.917 .916 .035 & investimento 06 & 0,925091 \\
\hline 4 & municipal 06 & 71 & aceleração 01 & 77 & investimento 06 & 20 & inst. pesquisa 03 & 0.473896 & empresa-filha 35 & 1.865 .460 .263 & federal 07 & 0,839125 \\
\hline 5 & aceleração 01 & 69 & municipal 06 & 75 & Unicamp 19 & 18 & Unicamp 33 & 0.45974 & municipal 06 & 1.647 .873 .052 & aceleração 01 & 0,80882 \\
\hline 6 & inst. pesquisa 03 & 57 & inst. pesquisa 03 & 63 & organização 45 & 17 & inst. pesquisa 08 & 0.442029 & aceleração 01 & 1.528 .920 .617 & ensino e pesquisa 37 & 0,780551 \\
\hline 7 & empresa-filha 35 & 50 & empresa-filha 35 & 50 & aceleração 01 & 16 & empresa-filha 35 & 0.441397 & organização 38 & 1.003 .312 .771 & organização 38 & 0,760045 \\
\hline 8 & Unicamp 40 & 39 & Unicamp 40 & 42 & inst. pesquisa 03 & 16 & aceleração 01 & 0.427021 & Unicamp 40 & 643.095 .058 & inst. pesquisa 03 & 0,747495 \\
\hline 9 & inst. pesquisa 08 & 37 & organização 17 & 39 & organização 38 & 15 & organização 38 & 0.422434 & empresa-filha 50 & 640.543 .218 & organização 20 & 0,69322 \\
\hline 10 & organização 38 & 35 & inst. pesquisa 08 & 37 & Unicamp 01 & 15 & organização 17 & 0.415991 & empresa-filha 17 & 590.816 .667 & inst. pesquisa 05 & 0,690968 \\
\hline 11 & organização 17 & 35 & organização 38 & 37 & ensino e pesquisa 37 & 14 & empresa-filha 55 & 0.405034 & empresa-filha 10 & 521.363 .961 & Unicamp 01 & 0,672429 \\
\hline 12 & organização 20 & 34 & organização 20 & 35 & incubadora 06 & 14 & Unicamp 40 & 0.40411 & Unicamp 33 & 492.722 .114 & estadual 05 & 0,664174 \\
\hline 13 & empresa-filha 23 & 30 & empresa-filha 51 & 31 & hub 08 & 13 & empresa-filha 50 & 0.398649 & empresa-filha 47 & 429.092 .532 & empresa-filha 38 & 0,652468 \\
\hline 14 & inst. pesquisa 05 & 26 & empresa-filha 23 & 30 & federal 05 & 13 & estadual 11 & 0.390456 & inst. pesquisa 05 & 383.319 .408 & municipal 06 & 0,64741 \\
\hline 15 & empresa-filha 55 & 24 & empresa-filha 55 & 28 & municipal 06 & 11 & empresa-filha 51 & 0.383891 & organização 20 & 368.760 .678 & \begin{tabular}{|l|} 
estadual 12 \\
\end{tabular} & 0,643143 \\
\hline 16 & empresa-filha 50 & 23 & estadual 11 & 27 & inst. pesquisa 05 & 11 & empresa-filha 41 & 0.383387 & empresa-filha 21 & 347.652 .381 & empresa-filha 13 & 0,637078 \\
\hline 17 & estadual 11 & 23 & inst. pesquisa 05 & 26 & inst. pesquisa 21 & 11 & empresa-filha 22 & 0.382508 & inst. pesquisa 21 & 306.441 .955 & organização 45 & 0,618641 \\
\hline 18 & empresa-filha 10 & 22 & empresa-filha 25 & 25 & Unicamp 29 & 11 & organização 20 & 0.381466 & organização 15 & 293.753 .968 & federal 12 & 0,609875 \\
\hline 19 & empresa-filha 25 & 22 & empresa-filha 50 & 23 & ensino e pesquisa 71 & 11 & inst. pesquisa 21 & 0.36875 & empresa-filha 55 & 280.052 .201 & estadual 10 & 0,603136 \\
\hline 20 & organização 15 & 22 & organização 15 & 23 & organização 18 & 10 & empresa-filha 53 & 0.366428 & empresa-filha 53 & 215.872 .006 & hub 08 & 0,588024 \\
\hline
\end{tabular}

Fonte: elaboração própria, utilizando o software Gephi.

Nota: essa tabela mostra somente os vinte maiores valores obtidos para cada estatística.

DOI: $10.14211 /$ xi-egepe- 118100

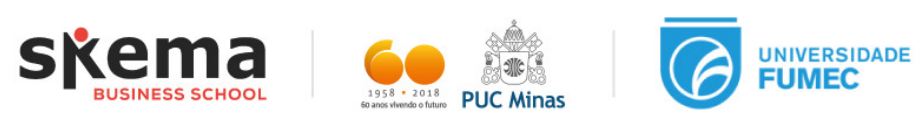

$\underset{\substack{\text { Universidade } \\ \text { vederal }}}{\mathfrak{f e p}}$

RS

FUNJEP

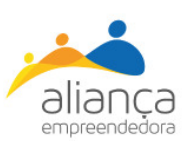


empresas-filhas, que apareceram três vezes (empresa-filha 35, empresa-filha 50 e empresa-filha $55)$.

Por fim, tem-se que duas das organizações mais importantes para o EE, o órgão da administração pública "estadual 06 " e organização da sociedade civil "organização 17" são externas à RMC. Isso corrobora com a literatura sobre EE sobre a necessidade de se investigar como são feitas e qual a importância das conexões que as organizações de um dado ecossistema realizam com elementos fora de seus limites geográficos, qual o alcance dessas conexões ou mesmo em questionar quais são os próprios condicionantes geográficos de um EE.

Tabela 3. Principais organizações do Ecossistema Empreendedor da RMC, a partir das suas medidas de centralidade na rede

\begin{tabular}{|c|c|c|c|}
\hline $\begin{array}{c}\text { Frequência nos } \\
\text { rankings de } \\
\text { centralidade }\end{array}$ & Codinome & $\begin{array}{c}\text { Interno / } \\
\text { externo à } \\
\text { RMC }\end{array}$ & Categoria \\
\hline \multirow{6}{*}{6} & aceleração 01 & interno & espaços / ambientes de empreendedorismo \\
\hline & estadual 06 & externo & adm. pública estadual \\
\hline & inst. pesquisa 03 & interno & instituto de pesquisa \\
\hline & municipal 06 & interno & adm. pública municipal \\
\hline & organização 38 & interno & organização da sociedade civil \\
\hline & Unicamp 33 & interno & instituto/depto./entidade estudantil da Unicamp \\
\hline \multirow{3}{*}{5} & inst. pesquisa 05 & interno & instituto de pesquisa \\
\hline & organização 18 & interno & organização da sociedade civil \\
\hline & organização 20 & interno & organização da sociedade civil \\
\hline \multirow{4}{*}{4} & empresa-filha 35 & interno & empresa-filha da Unicamp \\
\hline & empresa-filha 50 & interno & empresa-filha da Unicamp \\
\hline & empresa-filha 55 & interno & empresa-filha da Unicamp \\
\hline & Unicamp 40 & interno & instituto/depto./entidade estudantil da Unicamp \\
\hline \multirow{5}{*}{3} & estadual 11 & interno & adm. pública estadual \\
\hline & inst. pesquisa 08 & interno & instituto de pesquisa \\
\hline & inst. pesquisa 21 & interno & instituto de pesquisa \\
\hline & organização 15 & interno & organização da sociedade civil \\
\hline & organização 17 & externo & organização da sociedade civil \\
\hline
\end{tabular}

Fonte: elaboração própria.

\section{CONSIDERAÇÕES FINAIS}

O caráter sistêmico de Ecossistemas Empreendedores ainda é pouco compreendido, faltando clareza quanto ao modo em que esses agentes estão conectados e quais interações são as mais relevantes (Stam, 2015). A principal contribuição deste trabalho é avançar nessa compreensão a partir do estudo da rede de relações entre as organizações que constituem o ecossistema. Destarte, foi evidenciada a importância de se pensar o ecossistema como uma estrutura de relações entre os atores e não somente como elementos desconexos. Isso implica que as políticas de estímulo ao empreendedorismo devem mirar nesta dinâmica de formação de laços como um elemento crítico. A mera presença de agentes isolados não constitui a lógica ecossistêmica.

Dentro do escopo do empreendedorismo acadêmico, os resultados desta pesquisa

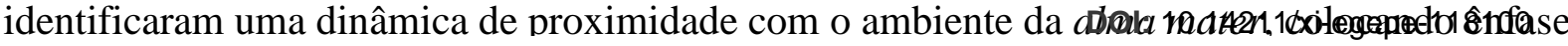


no papel da universidade como eixo estruturante do Ecossistema de Empreendedorismo, corroborando achados recentes (Schaeffer et al., 2018). Assim, percebe-se um papel da universidade de conectar agentes dispersos em uma estratégia para que sejam formados novos empreendimentos. Com essas atividades de promoção empreendedora, as universidades interagem e modificam o seu entorno, tendo o potencial de engendrar alterações significativas nas estruturas produtivas e nas redes de relações organizacionais dos espaços em que atua (Miller \& Ács, 2017).

Por outro lado, os resultados da pesquisa sugerem que as instituições de apoio ao empreendedorismo formam o tecido de relações mais amplo que sustenta o ecossistema estudado. Enquanto houve um certo equilíbrio no número de instituições de apoio e de empresas, os primeiros se mostraram muito mais conectados, cumprindo a tarefa de ligar os outros elementos do ecossistema entre si de forma indireta. Neste sentido, nota-se um alto grau de funcionalidade no Ecossistema de Empreendedorismo da Região Metropolitana de Campinas, ainda que isto não evidencie um alto grau de maturidade para esta estrutura, tendo em conta os níveis relativos de integração das empresas nestes relacionamentos.

Um ponto alinhado a esta perspectiva e que foi salientado nos resultados diz respeito à relevância dos espaços/ambientes de empreendedorismo. Estes incluem aceleradoras, incubadoras, parques científico-tecnológico e espaços de coworking, os quais efetivamente são percebidos como instituições valiosas para o ecossistema (Fini et al., 2011). Neste sentido, o ecossistema analisado demonstra uma estrutura de governança bem desenvolvida, carecendo de maiores níveis de organicidade nas interações entre empresas, um vetor essencial para o processo evolutivo do ambiente empreendedor local (Saxenian, 1990).

A pesquisa, ao aplicar a metodologia ARS, também permitiu identificar quais são as organizações do Ecossistema Empreendedor da RMC e classificá-las em categorias. Este sistema permitiu mapear dois tipos principais (empresas ou instituições de apoio ao empreendedorismo), 11 subtipos de primeira ordem e 43 subtipos de segunda ordem. Isso ampliou o conhecimento que se havia sobre quem são os agentes que constituem um Ecossistema Empreendedor, resultado que transborda para além do caso estudado. Neste sentido, a contribuição metodológica do presente estudo oferece parâmetros para novos estudos que lidem com a temática de Ecossistemas de Empreendedorismo, possibilitando análises comparativas.

Estudos futuros também devem contemplar em maior profundidade as características e conteúdo das ligações e sua direcionalidade, aspectos não abordados nesta pesquisa. Também é promissora a ideia de investigar como se relacionam a estrutura da rede com os outros elementos do ecossistema, bem como quais os efeitos de políticas na rede. Redes podem, inclusive, servir como um medidor desses efeitos e também auxiliar na compreensão de outros condicionantes para o ecossistema, em especial normas sociais intrínsecas à rede e cultura. Outra linha de investigação promissora é verificar quais relações causais podem ser analisadas. Um caso de interesse nesta perspectiva diz respeito à verificação da associação entre o desempenho empresarial com as características gerais da rede em que estas organizações participam.

\section{REFERÊNCIAS}

Aaboen, L., Laage-Hellman, J., Lind, F., Öberg, C., \& Shih, T. (2016). Exploring the roles of university spin-offs in business networks. Industrial Marketing Management, 59, 157-166.

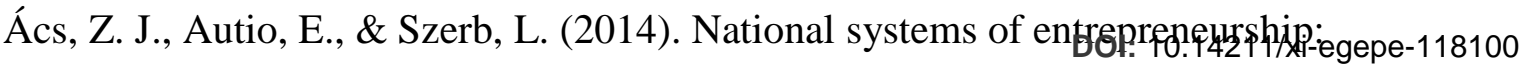


Alvedalen, J., \& Boschma, R. (2017). A critical review of entrepreneurial ecosystems research: towards a future research agenda. European Planning Studies, 25(6), 887-903.

Asheim, B., Smith, H., \& Oughton, C. (2011). Regional Innovation Systems: Theory, Empirics and Policy. Regional Studies, 45(7), 875-891.

Audretsch, D. B., \& Belitski, M. (2017). Entrepreneurial ecosystems in cities: establishing the framework conditions. Journal of Technology Transfer, 42(5), 1030-1051.

Auerswald, P. (2015). Enabling entrepreneurial ecosystems. In D. Audretsch, A. Link, \& M. L. Walsok (Eds.), The Oxford handbook of local competitiveness (pp. 54-83). Oxford: Oxford University Press.

Bagnato, V. S. et al. (2017). Ambientes empreendedores e o papel dos NIT. In: MORI, M. et al. Inovação em rede: boas práticas de gestão em NITs[ S.I: s.n.].

Beckman, C., Eisenhardt, K., Kotha, S., Meyer, A., \& Rajagopalan, N. (2012). Technology entrepreneurship. Strategic Entrepreneurship Journal, 6(2), 89-93.

Bell, G. G. (2005). Clusters, Networks, and Firm Innovativeness. Strategic Management Journal, 26(3), 287-295.

Bercovitz, J., \& Feldman, M. (2006). Entrepreneurial universities and technology transfer: a conceptual framework for understanding knowledge-based economic development. Journal of Technology Transfer, 31(1), 175-188.

Bruns, K., Bosma, N., Sanders, M., \& Schramm, M. (2017). Searching for the existence of entrepreneurial ecosystems: a regional cross-section growth regression approach. Small Business Economics, 49(1), 31-54.

Burt, R. S., Kilduff, M., \& Tasselli, S. (2013). Social Network Analysis: Foundations and Frontiers on Advantage. Annual Review of Psychology, 64(1), 527-547.

Cassiolato, J. E., \& Lastres, H. M. M. (2002). O enfoque em sistemas produtivos e inovações locais. In: Fischer, T. (Org.). Gestão do desenvolvimento e poderes locais: marcos teóricos e avaliação. Salvador: Casa da Qualidade. pp. 61-76.

Carree, M., \& Thurik, R. (2003). The impact of entrepreneurship on economic growth. In D.B. Audretsch, Z.J. Acs. Handbook of Entrepreneurship Research (Eds.) Kluwer Academic Publishers, Boston, pp. 437-471.

Chiesa, V., \& Piccaluga, A. (2000). Exploitation and diffusion of public research: the case of academic spin-off companies in Italy. $R \& D$ Management, 30(3), 329-339.

Cohen, B. (2006). Sustainable valley entrepreneurial ecosystems. Business Strategy and the Environment, 15(1), 1-14.

Conti, S. (2005). Espaço global versus espaço local: perspectiva sistêmica do desenvolvimento local. In: Diniz, C. C., Lemos, M. B. (Org.). Economia e território. Belo Horizonte: Editora UFMG. p. 209-252. 2005.

Diánez-González, J. P., \& Camelo-Ordaz, C. (2017). The influence of the structure of social networks on academic spin-offs' entrepreneurial orientation. Industrial Marketing Management, Forthcoming.

Etzkowitz, H. (2004). The evolution of the entrepreneurial univeฐoity 
Etzkowitz, H. (1998). The norms of entrepreneurial science: cognitive effects of the new university-industry linkages. Research Policy, 27(8), 823-833.

Etzkowitz, H., \& Leydesdorff, L. (2000). The dynamics of innovation: from National Systems and "Mode 2"' to a Triple Helix of university-industry-government relations. Research Policy, 29(2), 109-123.

Fini, R., Grimaldi, R., Santoni S., \& Sobrero, M. (2011). Complements or substitutes? The role of universities and local context in supporting the creation of academic spin-offs. Research Policy, 40(8), 1113-1127.

Furtado, A. (2005). Novos Arranjos Produtivos, Estado e Gestão da Pesquisa Pública. Revista Ciência e Cultura - Temas e Tendência. SBPC, ano 57, n. 1.

Galan-Muros, V., \& Davey, T. (2017). The UBC ecosystem: putting together a comprehensive framework for university-business cooperation. Journal of Technology Transfer, p. 1-36.

Gerhardt, T. et al. (2009). Estrutura do Projeto de Pesquisa. In: Gerhardt, T., \& Silveira, D. (org.). Métodos de Pesquisa. Porto Alegre: UFRGS.

Grimaldi, R., Kenney, M., Siegel, D.S., \& Wright, M. (2011). 30 years after Bayh-Dole: Reassessing academic entrepreneurship. Research Policy, 40(8), 1045-1057.

Guerrero, M., \& Urbano, D. (2012). The development of an entrepreneurial university. Journal of Technology Transfer, 37(1), 43-74.

Hayter, C., Nelson, A., Zayed, S., \& O’Connor, A. (2018). Conceptualizing academic entrepreneurship ecosystems: a review, analysis and extension of the literature. Journal of Technology Transfer, 43(4), 1039-1082.

Isenberg, D. (2010). How to start an entrepreneurial revolution. Harvard Business Review, 88(6), 40-51.

Hoang, H., \& Antoncic, B. (2003). Network-based research in entrepreneurship: A critical review. Journal of Business Venturing, 18(2), 165-187.

Leyden, D. P, Link, A. N., \& Siegel, D. S. (2014). A theoretical analysis of the role of social networks in entrepreneurship. Research Policy, 43(7), 1157-1163.

Mason, C., \& Brown, R. (2014). Entrepreneurial ecosystems and growth oriented entrepreneurship. Background paper prepared for the workshop organised by the OECD LEED Programme and the Dutch Ministry of Economic Affairs on Entrepreneurial Ecosystems and Growth Oriented Entrepreneurship, The Hague, Netherlands. 2014.

Miller, D., \& Ács, Z. (2017). The campus as entrepreneurial ecosystem: the University of Chicago. Small Business Economics, 49(1), 75-95.

Napier, G., \& Hansen, C. (2011). Ecosystems for young scalable firms. Copenhagen: FORA Group.

Pamplona, J.O. (2012). Technology Policy, Network Governance and Firm-level Innovation in the Software Industry: a Comparison of Two Brazilian Software Networks. Science and Technology Policy Research (SPRU). University of Sussex, Brighton, 
Qian, H., Ács, Z. J., \& Stough, R. R. (2013). Regional systems of entrepreneurship: The nexus of human capital, knowledge and new firm formation. Journal of Economic Geography, 13(4), 559-587.

Rothaermel, F., \& Ku, D. (2008). Intercluster innovation differentials: The role of research universities. IEEE Transactions on Engineering Management, 55(1), 9-22.

Ruffoni, J. (2010). Proximidade geográfica e inovação tecnológica de firmas: uma análise para o segmento produtor de máquinas para calçados da Itália e do Brasil. Tese (Doutorado em política científica e tecnológica) Instituto de Geociências. UNICAMP, Campinas, SP [s.n.], 2010.

Saxenian, A. (1990). Regional Networks and the Resurgence of Silicon Valley. California Management Review, 33, 89-112.

Schaeffer, P., Fischer, B., \& Queiroz, S. (2018). Beyond education: the role of research universities in innovation ecosystems. Foresight and STI Governance, 12(2), 50-61.

Shane, S., \& Venkataraman, S. (2000). The promise of entrepreneurship as a field of research. Academy of Management Review, 25, 217-226.

Siegel, D. S., \& Wright, M. (2015). Academic Entrepreneurship: Time for a Rethink? British Journal of Management, 26(4), 582-595.

Silva, G. M., \& Neves, J. A. B. (2013). Divisão do trabalho social e arranjos produtivos locais: reflexos econômicos de efeitos morais de redes interorganizacionais. Revista de Administração Mackenzie, 14(1), 202-228.

Soetanto, D., \& Van Geenhuizen, M. (2014). Getting the right balance: University networks' influence on spin-offs' attraction of funding for innovation. Technovation, 36/37, 26-38.

Stam, E. (2015). Entrepreneurial ecosystems and regional policy: a sympathetic critique. European Planning Studies, 23(9), 1759-1769.

Stam, E., \& Spigel, B. (2017). Entrepreneurial ecosystems. In R. Blackburn, D. De Clercq, J. Heinonen, \& Z. Wang (Eds.), The SAGE handbook of small business and entrepreneurship. London: SAGE. 2017.

Stam, W., Arzlanian, S., \& Elfring. T. (2013). Social capital of entrepreneurs and small firm performance: A meta-analysis of contextual and methodological moderators. Journal of Business Venturing, 29(1), 152-173.

Van de Ven, H. (1993). The development of an infrastructure for entrepreneurship. Journal of Business Venturing, 8(3), 211-230.

Wasserman, S. \& Faust, K. (1994). Social Network Analysis. New York: Cambridge University Press.

Wessner. C. (2013). Best Practices in State and Regional Innovation Initiatives: Competing in the 21st Century. Washington (DC): National Academies Press, 156-176. 